\title{
Severe acute maternal morbidity: study of epidemiology and risk factors
}

\author{
Mridu Sinha*, J. K. Goel, Shanti Sah, Ruchica Goel, Rajani Chaurasia
}

Department of Obstetrics and Gynaecology, Sri Ram Murti Smarak Institute of Medical Sciences, Bareilly, India

Received: 07 June 2016

Accepted: 25 June 2016

\section{*Correspondence:}

Dr. Mridu Sinha,

E-mail: sinhamridu72@gmail.com

Copyright: $\odot$ the author(s), publisher and licensee Medip Academy. This is an open-access article distributed under the terms of the Creative Commons Attribution Non-Commercial License, which permits unrestricted non-commercial use, distribution, and reproduction in any medium, provided the original work is properly cited.

\section{ABSTRACT}

Background: For last decade, severe acute maternal morbidity (SAMM) has emerged as a promising alternative to maternal mortality reviews. Maternal mortality may represent the tip of iceberg whose large base is formed by SAMM. The objective was to study the cases of critically ill obstetric i.e. pregnant and puerperal patients requiring intensive care due to severe acute maternal morbidity (near miss cases) and to analyze the common preventable risk factors associated with them.

Methods: This is a retrospective cohort study of women admitted during pregnancy or within 6 weeks postpartum, to multidisciplinary intensive care unit (ICU) of a tertiary-care teaching hospital, Sri Ram Murti Smarak Institute of Medical Sciences, Bareilly, UP, India, from April 2013 to April 2016. The data was collected pertaining to demographics, obstetric history, any pre-existing medical illness, reasons for admission to ICU, treatment given and their outcome in terms of maternal morbidity and mortality.

Results: The study found the prevalence of SAMM to be $1.87 \%$. The average age of admission was 26.6 years and most were primigravidas (42\%), unbooked (97\%) coming from rural areas $(75 \%)$. The most common obstetric cause of ICU admission was hypertensive disorders of pregnancy and the most common non-obstetric cause was sepsis. Maternal mortality index was $25.8 \%$ and fetal mortality rate was 257 per 1000 births among SAMM cases.

Conclusions: Study of risk factors associated with SAMM can provide important contributions to improve quality of available health care system in order to achieve reduction in maternal mortality.

Keywords: SAMM, Maternal mortality, ICU

\section{INTRODUCTION}

Many complications can occur during pregnancy and delivery that necessitates admission to intensive care unit. Worldwide, maternal mortality is the most commonly used indicator to assess the quality of prevailing maternal health-care services. According to global health observatory data, in 2015 there were 830 maternal deaths per day all over the world due to complications of pregnancy and delivery of which 550 were in subSaharan Africa and 180 in Southern Asia compared to 5 in developed countries. ${ }^{1}$ As maternal mortality is declining in many areas of developing world, its study alone may not be sufficient enough to provide information on quality of care given. Recently, the emphasis is more on severe acute maternal morbidity (SAMM) which has emerged as a promising alternative to maternal mortality reviews. However, the routine use of SAMM as an indicator is limited due to lack of uniform criteria for case identification. This term has advantage over maternal mortality as it draws attention to surviving women's reproductive health, and is equally applicable to developing as well as developed countries. ${ }^{2}$

Morbidity during pregnancy represents a continuum between extremes of good health and death, which can be 
uncomplicated, complicated, severely complicated or life-threatening and a lady may recover, may be temporarily or permanently disabled or she may die.

Severe acute maternal morbidity (SAMM), also known as "near miss" is defined as "a very ill pregnant or recently delivered woman who would have died had it not been that luck and good care was on her side". ${ }^{3}$ In literature, three different criterion have been proposed to identify "near miss" cases or SAMM.,

- Disease-specific criteria e.g. pre-eclampsia, antepartum or postpartum haemorrhage.

- Organ-specific dysfunction or failure (specific criteria used for each organ-system).

- Management-specific e.g. admission to ICU, hysterectomy. ${ }^{6}$

Disease-specific criteria is useful if there is a clear-cut entity but if it becomes complicated e.g multiple organ dysfunction syndrome (MODS) or disseminated intravascular coagulation (DIC) then its interpretation becomes difficult, so it is not much favoured. Regarding organ-system based criteria, this may be the most accurate definition of life-threatening complication as very severe end-points are selected, but it depends on management received (e.g. ICU care) and also it requires technologies which may not be available in many hospitals. ${ }^{7}$ Lastly, the most frequently used managementspecific criteria, a case is identified by admission to ICU as it is simple, has lesser variation, easy to measure and data collection. In addition, this also includes nonobstetrical medical or surgical conditions that may become life-threatening and lead to death e.g. acute pancreatitis, intestinal perforation etc.

This clinically based definition permits an effective audit of maternal care as it reflects the pattern of maternal death. Hence, this study was undertaken to study the epidemiology of ICU admissions during pregnancy and postpartum to collect data about women with severe morbidity and to support the need for improvement in available health-care service delivery.

\section{METHODS}

The medical records of all critically ill obstetric patients admitted to intensive care unit (ICU) of Sri Ram Murti Smarak Institute of Medical Sciences, Bareilly, Uttar Pradesh, India during April 2013 to April 2016 were reviewed. This institution is a 950 bed tertiary-care teaching hospital with 42 bed multidisciplinary ICU, providing care to critically ill medical and surgical obstetric patients. Although ICU intensivists along with consultants from other respective departments such as cardiologist, pulmonologist, nephrologist, neurophysician, gastroenterologist etc. treat all critically ill obstetric patients admitted to ICU, obstetric complications are dealt by gynaecologists and combined decisions are made.
Datas were collected regarding age, parity, weeks of gestation at the time of admission, reason for admission, pregnancy-related and other medical diagnosis, treatment given, delivery details and their final outcome in terms of perinatal and maternal mortality or recovery. Patient selection criteria was pregnant or within 42 days of termination of pregnancy. After satisfying the selection criteria, they were broadly divided into two groups: antenatal and postnatal. Antenatal group was further divided into early pregnancy and late pregnancy complications according to their time of presentation in weeks of gestation. Any complications occuring before 24 weeks of gestation i.e. before period of viability were kept in early antenatal group whereas those presenting after 24 weeks were kept in late antenatal group. Diseases responsible for critical illness were categorized into obstetric and non-obstetric cause. Conditions that prompted ICU admissions were again divided into hemodynamic instability, respiratory insufficiency, neurological dysfunction. A new index called mortality index was defined as ratio of maternal deaths among SAMM to sum of SAMM and maternal deaths expressed as percentage. ${ }^{7}$ It gives an idea about what proportion of SAMM would ultimately succumb to death and how effective the health care service is with respect to managing the disease process. Fetal mortality rate was calculated by dividing the total number of fetal deaths after 24 weeks of pregnancy till delivery by the sum of all births (fetal deaths and live births after 24 weeks) during the same period among SAMM cases.

Statistical analysis was performed using MS Excel 2010 and results were expressed in terms of frequency and percentage.

\section{RESULTS}

During the study period, 151 obstetric patients who were satisfying the above-mentioned selection criteria were taken into consideration out of which 25 patients who went LAMA, were excluded (Figure 1). Thus with total 8051 deliveries in the same institution during that period, it gave the prevalence rate of $1.87 \%$. Out of remaining 126 study populations, 87 (69\%) patients survived but 39 (31\%) patients succumbed to death (Figure 2).

Total number of patients recruited for study

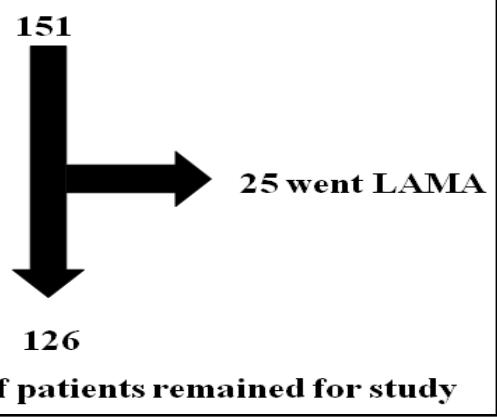

Total number of patients remained for study 


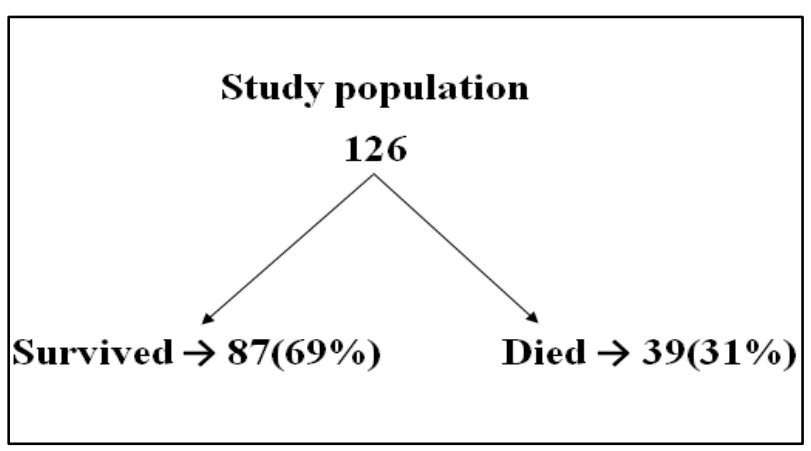

Figure 2: Final outcome of study population.

The most common age-group was between 21-25 years (48\%), with average of 26.6 years (Table 1).
Approximately $75 \%$ patients were from rural areas and majority $(97 \%)$ were unbooked. Majority were antenatal patients making $76 \%(n=97)$ of total obstetric ICU admission, rest $23 \%(n=29)$ were postnatal patients.

Table 1: Distribution of obstetric ICU patients according to age.

\begin{tabular}{|lll|}
\hline $\begin{array}{l}\text { Age-group } \\
\text { (years) }\end{array}$ & Number of patients & $\begin{array}{l}\text { Percentage } \\
\text { distribution }\end{array}$ \\
\hline$\leq 20$ & 5 & $4 \%$ \\
\hline $21-25$ & 60 & $48 \%$ \\
\hline $26-30$ & 39 & $31 \%$ \\
\hline $31-35$ & 14 & $11 \%$ \\
\hline$>35$ & 8 & $6 \%$ \\
\hline Total & 126 & $100 \%$ \\
\hline
\end{tabular}

Table 2. Distribution of obstetric ICU patients according to time of presentation.

\begin{tabular}{|lllll|}
\hline $\begin{array}{l}\text { Early pregnancy } \\
\text { complications }\end{array}$ & $\begin{array}{l}\text { Late pregnancy } \\
\text { complications }\end{array}$ & $\begin{array}{l}\text { Post-delivery } \\
\text { complications }\end{array}$ & $\begin{array}{l}\text { Post-operative } \\
\text { complications }\end{array}$ & $\begin{array}{l}\text { Total no. of } \\
\text { patients }\end{array}$ \\
\hline $19(15 \%)$ & $78(62 \%)$ & $13(10 \%)$ & $16(13 \%)$ & $126(100 \%)$ \\
\hline $\begin{array}{l}\text { Total number of } \\
\text { antenatal patients }\end{array}$ & $=97(76 \%)$ & $\begin{array}{l}\text { Total number of postnatal } \\
\text { patients }\end{array}$ & $=29(23 \%)$ & $126(100 \%)$ \\
\hline
\end{tabular}

Table 3: Parity-wise distribution of obstetric ICU patients.

\begin{tabular}{|ll|l|}
\hline Gravida or parity & $\begin{array}{l}\text { Number of } \\
\text { patients }\end{array}$ & $\begin{array}{l}\text { Percentage } \\
\text { distribution }\end{array}$ \\
\hline One (primi) & 53 & $42 \%$ \\
\hline Two & 31 & $25 \%$ \\
\hline Three & 14 & $11 \%$ \\
\hline Four and above (multi) & 28 & $22 \%$ \\
\hline Total & 126 & $100 \%$ \\
\hline
\end{tabular}

Table 4: Early pregnancy ( $<24$ weeks) complications leading to ICU admission.

\begin{tabular}{|lll|}
\hline Causes & $\begin{array}{l}\text { Number } \\
\text { of } \\
\text { patients }\end{array}$ & $\begin{array}{l}\text { Percentage as } \\
\text { compared to } \\
\text { whole }\end{array}$ \\
\hline Abortion-related & 9 & $7.1 \%$ \\
\hline Ectopic pregnancy & 4 & $3.1 \%$ \\
\hline Uterine perforation & 2 & $1.5 \%$ \\
\hline Molar pregnancy & 2 & $1.5 \%$ \\
\hline Surgical-pancreatitis & 1 & $0.7 \%$ \\
\hline Surgical-appendicitis & 1 & $0.7 \%$ \\
\hline Total & 19 & $14.6 \%$ \\
\hline
\end{tabular}

Among antenatal patients, most i.e. $62 \%(n=78)$ of them presented in later period of gestation, with average of 34.6 weeks gestation and among postnatal patients, there was marginally increase in operated complicated patients $(13 \%)$ as compared to those delivered vaginally $(10 \%)$ (Table 2).
According to parity-wise distribution, most (42\%) $(n=53)$ of the patients presented in their first pregnancy, followed by $(25 \%) \quad(n=31)$ in second pregnancy and then multigravidas or multiparas $(22 \%)(n=28)$ (Table 3$)$.

Table 5: Obstetric causes of ICU admission (many had more than one causes).

\begin{tabular}{|lll|}
\hline $\begin{array}{l}\text { Late pregnancy-related } \\
\text { causes }\end{array}$ & $\begin{array}{l}\text { Number of } \\
\text { patients }\end{array}$ & Percentage \\
\hline $\begin{array}{l}\text { Hypertensive disorders of } \\
\text { pregnancy }\end{array}$ & 28 & $22.2 \%$ \\
\hline LSCS-related complications & 20 & $15.8 \%$ \\
\hline Antepartum haemorrhage & 7 & $5.5 \%$ \\
\hline Postpartum haemorrhage & 8 & $6.3 \%$ \\
\hline $\begin{array}{l}\text { Rupture uterus/ prev.scar } \\
\text { dehiscence }\end{array}$ & 4 & $3.2 \%$ \\
\hline $\begin{array}{l}\text { Premature rupture of } \\
\text { membranes }\end{array}$ & 3 & $2.4 \%$ \\
\hline Labour complications & 2 & $1.6 \%$ \\
\hline Cholestasis of pregnancy & 2 & $1.6 \%$ \\
\hline Amniotic fluid embolism & 1 & $0.7 \%$ \\
\hline
\end{tabular}

Abortion-related complications was the most common cause seeking ICU admission in early pregnancy complication group (Table 4). The most common obstetric cause of ICU admission in late pregnancy was hypertensive disorders of pregnancy whereas the most common non-obstetric cause was sepsis (Table 5, 6). Most of them had more than one complication. Hypertensive disorders of pregnancy comprised of gestational hypertension, pre-eclampsia and eclampsia. 
And the most common reason that prompted ICU admission was hemodynamic instability (27.2\%) followed by respiratory insufficiency.

Table 6: Non-obstetric causes of ICU admission (many had more than one causes).

\begin{tabular}{|lll|}
\hline $\begin{array}{l}\text { Non-pregnancy } \\
\text { related causes }\end{array}$ & $\begin{array}{l}\text { Number of } \\
\text { patients }\end{array}$ & Percentage \\
\hline Sepsis & 45 & $35.7 \%$ \\
\hline Cardiac-related & 20 & $15.8 \%$ \\
\hline DIC & 19 & $15 \%$ \\
\hline MODS & 15 & $11.9 \%$ \\
\hline Renal-complications & 14 & $11.1 \%$ \\
\hline Respiratory-related & 13 & $10.3 \%$ \\
\hline Hepatic causes & 6 & $4.8 \%$ \\
\hline Neurological & 5 & $3.9 \%$ \\
\hline $\begin{array}{l}\text { Hematological- } \\
\text { thrombocytopenia }\end{array}$ & 4 & $3.2 \%$ \\
\hline $\begin{array}{l}\text { Associated causes- } \\
\text { anemia }\end{array}$ & 20 & $15.9 \%$ \\
\hline Infections-dengue & 2 & $1.6 \%$ \\
\hline Infections-malaria & 2 & $1.6 \%$ \\
\hline
\end{tabular}

$49 \%$ of antenatal patients underwent LSCS, $29 \%$ delivered vaginally, 4 patients presented with rupture uterus whereas 11 patients died with fetus-in-utero. The average length of stay in ICU varied from 2 to 8 days. The calculated maternal mortality index was $25.8 \%$ and the most common cause associated with these patients was sepsis. The fetal mortality rate was calculated to be 257 per 1000 births among SAMM, in which majority were intrauterine demise beforehand.

\section{DISCUSSION}

Thus, in this retrospective study, the objective was to find out the most common cause of ICU admission, both obstetric and non-obstetric, their clinical course and the final outcome of all critically-ill obstetric patients admitted to ICU. The prevalence rate of this study $1.87 \%$ is comparable to a study by $\mathrm{WHO}$, where a prevalence rate of $(0.01 \%-2.99 \%)$ was found using managementspecific criteria. ${ }^{7}$ The most common age-groups of 21-25 years shows that comparatively younger age groups are involved. ${ }^{8}$ With $76 \%$ antenatal patients, this is in correlation with a study showing that the ICU admission profile of women was similar in developed and developing countries. ${ }^{9}$ As per the causes, both obstetric and non-obstetric, seeking ICU care, it shows that there is no change in common cause of ICU admissions over a last decade. ${ }^{10}$ Among early pregnancy complication group, abortion-related hospital admissions predominated. This emphasises the need of monitoring it and quantifying the magnitude of adverse health effects of unsafe abortion in developing countries like India. ${ }^{11}$ Although the most common obstetric cause of ICU admission was hypertensive disorders of pregnancy, they were responsible for only $5 \%$ of total maternal mortality.
Sepsis was the most common preventable cause found to be associated with mortality among SAMM cases (28\%). Hence, study and identification of SAMM cases gives an idea about its magnitude, to identify most frequent characteristics and clinical conditions which will help to recognize problems in antepartum services, peripheral health-care facilities and referral system. ${ }^{12}$

It is believed that the underlying diseases causing SAMM are the same as those causing maternal death. If this proves to be true, then studying the circumstances surrounding a woman with SAMM will act as a complement to analysis of maternal mortality and will allow for a rapid assessment of maternal care. But not only the clinical cause but also the social, cultural, economic and political determinants of health should also be considered. These factors can operate at three levels leading to delay in getting appropriate treatment. ${ }^{4}$

- Delay in deciding to seek care (phase 1 delay).

- Delay in identifying and reaching care (phase 2 delay).

- Delay in receiving appropriate care in hospital (phase 3 delay).

According to one study, the most frequent preventable factors were clinician related i.e. improper management of obstetric emergencies at referring hospitals, poor referral practices, and poor access or utilization of health care services. ${ }^{13}$ This idea of substandard care can suggest changes in clinical education programmes and policies to improve maternal outcome. ${ }^{14}$ Besides, continuous psychosocial follow up of those survived is necessary as their longterm health-related quality of life is impaired. ${ }^{15}$

There should be standardization of inclusion criteria as well as methods for case assessment to facilitate comparison over time and between countries. ${ }^{16}$ Lack of proper antenatal care and delay in ICU referral are easily preventable factors that affect outcome. ${ }^{17}$

Audit of SAMM cases help us to understand the spectrum from maternal morbidity to mortality.

Limitation of this study is that as it is a retrospective study and sample size is small, it cannot be applied to whole population. And as hospital records are the only source of information for data compilation, it underestimates the true incidence especially if events occurred outside and not recognized.

\section{CONCLUSION}

Study of risk factors associated with SAMM can provide important contributions to improve quality of available health care system to reduce maternal morbidity and mortality. Not only availability of health-care services are enough to achieve reduction in SAMM, but it must be accessible and affordable also. Proper antenatal care, skilled trained birth attendants (TBA), institutional 
deliveries, access to emergency obstetric care and a functional referral system are necessary to reduce it, apart from ICU.

\section{ACKNOWLEDGEMENTS}

The authors would like to acknowledge their medical records department, SRMS IMS, for their continuous and timely support.

\section{Funding: No funding sources}

Conflict of interest: None declared

Ethical approval: The study was approved by the Institutional Ethics Committee

\section{REFERENCES}

1. WHO. Maternal mortality. World Health Organization.2016. Available at www.who.int/ gho/ maternal_health/mortality/maternal_mortality_text/e $\mathrm{n} /$. Accessed on 26 March 2016.

2. Vais A, Bewley S, Severe acute maternal morbidity. In Lynch C, Keith LG, Lalonde AB, Karoshi M, eds. A Textbook of Postpartum Haemorrhage: A Comprehensive Guide to Evaluation, Management and Surgical Intervention, Special FOGSI Edition, Jaypee Publishers;2006:339.

3. Sekharan PK. An introduction to near-miss in obstetrics. In Arulmozhi Ramarajan ed, Severe acute maternal morbidity, New Delhi: Jaypee Publishers; 2011:3.

4. Akker T, Rhenen JV, Mwagomba B, Lommerse K, Vinkhumbo S, Roosmalen JV. Reduction of severe acute maternal morbidity and maternal mortality in thyolo district, malawi: the impact of obstetric audit. PLoS One. 2011;6(6):e20776.

5. Say L, Souza JP, Pattinson RC. WHO working group on maternal mortality and morbidity classifications. Maternal near-miss towards a standard tool for monitoring quality of maternal health care. Best Pract Res Clin Obstet Gynaecol. 2009;23:287-96.

6. Senanayake H, Dias T, Jayawardena A. Maternal mortality and morbidity: epidemiology of intensive care admissions in pregnancy. Best Pract Res Clin Obstet Gynaecol. 2013;27(6):811-20.
7. Say L, Pattinson RC, Gulmezoglu AM. WHO Systematic review of maternal morbidity and mortality : the prevalence of severe acute maternal morbidity (near miss). Reprod Health. 2004;1(1):3.

8. Bibi S, Memon A, Sheikh JM, Qureshi AH. Severe acute maternal morbidity and intensive care in a public sector university hospital of Pakistan. J Ayub Med Coll Abbottabad. 2008;20(1):109-12.

9. Pollock W, Rose L, Dennis CL. Pregnant and postpartum admissions to the intensive care unit: a systematic review. Intensive Care Med. 2010;36(9):1465-74.

10. Pattinson RC, Buchhman E, Mantel G, Schoon M, Rees H. Can enquiries into severe acute maternal morbidity act as a surrogate for maternal death enquiries? British J Obs Gynae. 2003;110(10):889-3.

11. Singh S. Hospital admissions resulting from unsafe abortions: estimates from 13 developing countries. Lancet. 2006;368:1887-92.

12. Kushwah B, Singh AP, Natung P. Analysis of various criteria for identification of severe acute maternal morbidity in a rural tertiary health care centre: a prospective one year study. Int J Med Sci Public Health. 2014;3(3):330-334.

13. Pandey A, Das V, Agarwal A, Agarwal S, Misra D, Jaiswal N. Evaluation of obstetric near miss and maternal deaths in a tertiary care hospital in North India: shifting focus from mortality to morbidity. J Obst Gynae India. 2014;64(6):394-399.

14. Lawton B, Macdonald EJ, Brown SA, Wilson L, Stanley J, Tait JD, et al. Preventability of severe acute maternal morbidity. Am J Obstet Gynecol. 2014;210:557-6.

15. Leung NY, Lau AC, Chan KK, Yan WW. Clinical characteristics and outcomes of obstetric patients admitted to the intensive care unit: a 10-year retrospective review. Hong Kong Med J. 2010;16(1):18-25.

16. Penney G, Brace V. Near miss audit in obstetrics. Curr Opin Obstet Gynecol. 2007;19(2):145-50.

17. Karnad DR, Lapsia V, Krishnan A, Salvi S. Prognostic factors in obstetric patients admitted to an Indian intensive care unit. Critical Care Medicine. 2004;32(6):1294-9.

Cite this article as: Sinha M, Goel JK, Sah S, Goel R, Chaurasia R. Severe acute maternal morbidity: study of epidemiology and risk factors. Int J Reprod Contracept Obstet Gynecol 2016;5:2141-5. 